\title{
Bradycardia during cold ocular irrigation under general anaesthesia: an example of the diving reflex
}

\begin{abstract}
A case of bradycardia is reported which was precipitated by cold normal saline applied to the eye during general anaesthesia. The history and physiology of the diving reflex is discussed and we believe that these data suggest that this patient's bradycardia was induced by the diving reflex, and not by the oculocardiac reflex.
\end{abstract}

Nous rapportons un cas bradycardie provoquée par l'application oculaire de soluté physiologique froid. La discussion porte sur l'histoire et la physiologie du réflexe de plongée. Nous croyons que ces données supportent notre hypothèse d'un bradycardie provoquée par le réflexe de plongée et non par le réflexe oculocardiaque.

The oculocardiac reflex, well-described in the anaesthesia literature, results from a variety of stimuli including traction on the extraocular muscles, ocular manipulation, pressure or traction on the globe, or pressure applied to an empty orbit. ${ }^{1-5}$ However, even in the absence of these stimuli, cold ocular irrigation may elicit bradycardia induced by the diving reflex. The oculocardiac reflex is active in awake and anaesthetized subjects and is manifested by a variety of dysrhythmias, which include bradycardia, bigeminy, ectopic beats, nodal rhythm, and asystole. ${ }^{6-8}$ The diving reflex may have similar physiological mechanisms and clinical significance.

\section{Key words}

HEART: arrhythmia;

BRADYCARDIA: diving reflex.

From the Departments of Anesthesiology, University of Wisconsin Clinical Science Center, ${ }^{*}$ Madison, Wisconsin and Emory University School of Medicine, $\nmid$ Atlanta, Georgia.

Address correspondence to: Dr. George A. Arndt, Department of Anesthesiology, University of Wisconsin Clinical Science Center, B6/387 CSC, 600 Highland Avenue, Madison, WI 53792.

Accepted for publication 22nd February, 1993.

\section{Case report}

A 60-yr-old woman was scheduled for left scleral buckle. Her past medical history was unremarkable, with no history of cardiovascular, neurological, renal, haematopoetic, endocrinological, or pulmonary disease. She did not smoke or use alcohol or take medications. Previously she had undergone two gynaecological operations during uncomplicated general anaesthesia. Physical examination was normal and there was no syncopal history. The preoperative laboratory results were normal, with haemoglobin and haematocrit $13.7 \mathrm{gm} \cdot \mathrm{dl}^{-1}$ and $39.7 \%$, respectively. The preoperative 12-lead electrocardiograph (ECG) showed normal sinus rhythm with no suggestion of ischaemia. The vital signs the day before surgery were blood pressure $140 / 80 \mathrm{mmHg}$, pulse 88 beats $\cdot \mathrm{min}^{-1}$ and respirations 18 breaths $\cdot \mathrm{min}^{-1}$. She weighed $55.7 \mathrm{~kg}$ and was $155 \mathrm{~cm}$ tall. Sixty minutes before her operation, the patient received diazepam $10 \mathrm{mg} p o$, and a peripheral $\dot{i v}$ infusion of lactated Ringer's solution with $5 \%$ dextrose.

Intraoperative monitoring included a five-lead continuous ECG which displayed limb lead II. After preoxygenation, anaesthesia was induced with thiopentone 275 $\mathrm{mg}$ and lidocaine $100 \mathrm{mg} i \mathrm{v}$. Tracheal intubation was facilitated with succinylcholine $80 \mathrm{mg} i v$, and was easily accomplished. Anaesthesia was maintained with $1 \%$ isoflurane and $50 \%$ nitrous oxide in oxygen. Ventilation was controlled so that end-tidal carbon dioxide concentration was $36 \mathrm{mmHg}$. Relaxation was maintained with $5 \mathrm{mg}$ $i v$ vecuronium bromide. Vital signs did not vary by more than $5 \%$ during anaesthetic induction and maintenance up to this point.

Fifteen minutes after induction, a watertight drape was placed around the left eye and the surgeon began to irrigate the eye liberally with sterile, room-temperature, normal saline. The temperature of the saline was $19.7^{\circ} \mathrm{C}$. The heart rate promptly decreased from 78 beats $\cdot \mathrm{min}^{-1}$ with normal sinus rhythm to a sinus bradycardia of 30 beats $\cdot \min ^{-1}$. The surgeon stopped the irrigation and atropine $0.4 \mathrm{mg}$ was given $i v$. The heart rate increased to 90 beats $\cdot \min ^{-1}$ with normal sinus rhythm. The episode 
of bradycardia was short-lived (lasting approximately 20 $\mathrm{sec}$ ), and quickly returned to an acceptable rate with atropine administration and cessation of irrigation. During the episode, no ocular stimulus was present other than application of cold saline; the surgeon had placed no retractors, instruments, retracted the eye muscles or placed pressure on the eye. Pulse oximetry revealed that the patient was not hypoxic during the episode, neither did she become hypotensive, the blood pressure remaining at $110 / 80$ as measured by auscultation before, during and after the episode. After the heart rate stabilized, the surgeon proceeded cautiously with ocular irrigation which caused no further change in vital signs. We were unable to record a rhythm strip during the episode. The drape was found to form a watertight seal, preventing the irrigation solution escaping from the field.

The remainder of anaesthesia was uneventful. The vital signs remained stable. At the end of the procedure muscle relaxation was reversed with glycopyrrolate and neostigmine with no change in heart rate. Emergence was uncomplicated and the tracheal tube was removed when the patient opened her eye. She was transferred to the recovery room and discharged when alert and awake. The postoperative visit the next day was unremarkable except for a mild sore throat.

\section{Discussion}

This case is an example of the diving reflex in an adult during general anaesthesia. Classically the diving reflex is described as bradycardia without hypotension during the application of cold irrigants to the distribution of the ophthalmic division of the fifth cranial nerve. Bradycardia is mediated by the vagus nerve. ${ }^{9,10}$ This reflex appears to be more prominent in children than in adults and has been used in both awake adults and children to treat refractory supraventricular tachycardia. ${ }^{11-14}$ It is a primal reflex and appears to be present in most vertebrates. It is more potent than a Valsalva manoeuvre, carotid massage or ocular compression in inducing vagally mediated bradycardia. ${ }^{15}$

The diving reflex was first described by Bert in 1879 while investigating duck asphyxiation. He found that water applied to the ducks' eyes and nostrils produced bradycardia, and ducks tolerated underwater asphyxiation longer than chickens. ${ }^{5,17}$ In 1894, Richet concluded that the duck's ability to tolerate long periods underwater was a reflex physiological adaptation, conserving available oxygen stores and allowing the animal to tolerate long periods without oxygen. He speculated that blood was preferentially shunted to more oxygen-dependent organs. ${ }^{16}$

The diving reflex was characterized in diving and nondiving animals years after the initial work of Bert and
Richet. The diving reflex is present in man, seals, and dogs. It is a highly integrated reflex consisting of initiating events which temporally summate to protect against asphyxiation under water. ${ }^{10,16,18}$ Clinically, the reflex has been induced using ice water. However, in man, the reflex is also initiated by facial application of $0-20^{\circ} \mathrm{C}$ cold saline. ${ }^{19}$ In our patient, the temperature was $19.7^{\circ} \mathrm{C}$ and fell within the $15-20^{\circ} \mathrm{C}$ range, the most frequently studied temperature range. ${ }^{20,21}$ Further general anaesthesia does not abolish the reflex in dogs and seals, ${ }^{22}$ but im or iv anticholinergic agents may block or antagonize the reflex. ${ }^{9}$ In seals, and perhaps in man, afferent information from the carotid body and sinus, mediated by the glossopharyngeal nerve, is important in sustaining the later portions of the reflex which includes vasoconstriction and apnea. ${ }^{22,23}$

Both the parasympathetic and sympathetic nervous systems are integral parts of the diving reflex. In dogs, bradycardia results from increased vagal tone, ${ }^{24,25}$ as the reflex is abolished with atropine. The sympathetic nervous system causes intense peripheral vasoconstriction which diverts blood flow from nonvital organs and maintains cardiac output, blood pressure and venous tone. ${ }^{23,24}$ Blood flow to the kidneys, muscles, and gut is minimized. Cardiac blood flow and cardiac output may decrease by $90 \%$ but the reflex protects blood flow to the heart, lungs, and brain. ${ }^{26}$ The diving reflex begins when temperature receptors in the ophthalmic division of cranial nerve five are excited by cold water. ${ }^{26}$ The sensory information proceeds to the sensory nucleus of the fifth cranial nerve and then to the vagal motor nucleus. ${ }^{26}$ Fifth cranial nerve sensory input also enters the brainstem cardioinhibitory centre and mediates the sympathetic response. ${ }^{26}$ The vagal motor nucleus and the cardioinhibitory centre also communicate with the respiratory centre. ${ }^{26}$ This produces a more intense reflex during exhalation. ${ }^{19,28}$ Only the brain maintains a normal or increased blood supply.,27

The diving reflex may have clinical importance. Death from arrhythmias due to the oculocardiac reflex are well known. ${ }^{6}$ The diving reflex is mediated by similar reflex arcs. In awake humans, the diving reflex appears to be more intense than the oculocardiac reflex. ${ }^{15,21}$ Bradycardia during the diving reflex is more profound than the maximal bradycardia of the oculocardiac reflex. ${ }^{15,21}$ The diving reflex also involves intense sympathetic nervous system activity altering myocardial repolarization as evidenced by T-wave and ST segment changes. ${ }^{29}$ The combination of slowed myocardial conduction, altered ventricular repolarization, and the propensity of the oculocardiac reflex to produce life-threatening arrhythmias implies that the diving reflex also may precipitate a potentially dangerous situation. ${ }^{29,30}$ The risk may be compounded in the elderly ophthalmology patient with 
multiple medical problems. In experienced pearl divers, two cases of idioventricular rhythms and other dysrhythmias during routine dives were attributed to the diving reflex. ${ }^{30}$ Wolf suggested that the diving reflex may be important as a possible mechanism of sudden death. ${ }^{31}$ The diving reflex may cause death in the immersion syndrome, but also enhances survival during long periods of cold-water immersion. ${ }^{32}$

The oculocardiac reflex and diving reflex are separate reflexes. Examination, however, reveals many similarities. Both reflexes are initiated by stimuli delivered in the distribution in the ophthalmic division of the fifth cranial nerve, are more intense during expiration, are mediated partially by the vagus nerve, and initiate physiological mechanisms to conserve oxygen. ${ }^{24} \mathrm{~A}$ variant of the diving reflex is even present in some fish to prevent asphyxiation in air. ${ }^{33}$ The diving reflex initiates bradycardia by sensing cold water, while the oculocardiac reflex initiates bradycardia by sensing pressure. The diving reflex may not be uncommon during anaesthesia but it is reported as the oculocardiac reflex because of a temporal relationship between the use of cold ocular irrigants and ocular manipulation. These reflexes, which may be evolutionary reflexes to protect against drowning, perhaps should be called "asphyxial protective reflexes." In mammals, the reflexes may prevent birth asphyxiation and explain their prominence in infants and children. ${ }^{17}$

\section{Conclusion}

This case demonstrates a possible diving reflex during general anaesthesia in a healthy, elderly woman. The clinical presentation was consistent with the diving reflex; none of the inciting stimuli required by the oculocardiac reflex were present. The response was classic: bradycardia without hypotension shortly after initiation of eye irrigation with cold $19.5^{\circ} \mathrm{C}$ saline. Irrigants of this temperature has produced bradycardia in awake humans and in diving and non-diving animal models during general anaesthesia. ${ }^{2,22,25,29}$ The bradycardia was reversed by administering $i v$ atropine and discontinuing the eye irrigation. The atropine prevented bradycardia recurrence.

The diving reflex is uncommon during ophthalmological surgery. ${ }^{10}$ In the elderly patient the diving reflex may present a similar risk to the patient as the oculocardiac reflex as they share similar pathways and physiological mechanisms. It is prudent to prevent the diving reflex by avoiding cold ocular irrigants. ${ }^{10}$ However, we do not recommend the routine use of anticholinergics because of the risk of tachycardia.

\section{References}

1 Alexander $J P$. Reflex disturbances of cardiac rhythm during ophthalmic surgery. Br J Ophthalmol 1975; 59: 518-23.
2 ApIvor D, Ravi PK. Ketamine and the oculocardiac reflex. Anaesthesia 1976; 31: 18-22.

3 Blanc VF, Hardy J, Milot J, Jacob J. The oculocardiac reflex: a graphic and statistical analysis in infants and children. Can Anaesth Soc J 1983; 30: 360-9.

4 Kerr $W J$, Vance $J P$. Oculocardiac reflex from the empty orbit. Anaesthesia 1983; 38: 883-5.

5 Mirakhur RK, Jones CJ, Dundee JW, Archer DB. IM or IV atropine or glycopyrrolate for the prevention of oculocardiac reflex in children undergoing squint surgery. $\mathrm{Br} \mathrm{J}$ Anaesth 1982; 54: 1059-63.

6 Katz RL, Bigger JT. Cardiac arrhythmias during anesthesia and operation. Anesthesiology 1970; 33: 193-212.

7 Donlon JV Anesthesia for eye, ear, nose and throat. In: Miller RD (Ed.). Anesthesia, 2nd ed. New York: Churchill Livingstone, 1986: 1837-94.

8 Smith RB, Douglas H, Petruscak J. The oculocardiac reflex and sino-atrial arrest. Can Anaesth Soc J 1972; 19: 138-41.

9 Andersen HT, Blix AS. Pharmacological exposure of components in the autonomic control of the diving reflex. Acta Physiol Scand 1974; 90: 381-6.

$10 \mathrm{Craig} A B$. Heart-rate responses to apneic underwater diving and to breath holding in man. J Appl Physiol 1963; 18 : 854-62.

11 Ciastko A. More on the diving reflex and supraventricular tachycardia (Letter). J Pediatr 1976; 93: 721-2.

12 Hamilton J, Moodie D, Levy J. The use of the diving reflex to terminate supraventricular tachycardia in a 2-week old infant. Am Heart J 1979; 97: 371-4.

13 Sacks $L M$, Smith RM. Ice-water washcloth rather than facial immersion (diving reflex) for supraventricular tachycardia in infants (correspond). Am J Candiol 1984; 15: 53: 988.

14 Tavsanoglu $S$, Özenel E. Ice-water washcloth rather than facial immersion (diving reflex) for supraventricular tachycardia in adults (correspond). Am J Cardiol 1985; 56: 1003.

15 Berk WA, Shea MJ, Crevey BJ. Bradycardic responses to vagally mediated bedside maneuvers in healthy volunteers. Am J Med 1991; 90: 725-9.

16 Andersen HT. Physiological adaptations in diving vertebrates. Physiol Rev 1966; 46: 212-43.

17 Irving $L$. Respiration in diving mammals. Physiol Rev 1939; 19: 112-34.

18 Irving $L$. On the ability of warm blooded animals to survive without breathing. Sci Mon NY 1934: 38: 422-8.

19 Khurana RK, Watabilki S, Hebel JR, Toro R, Nelson E. Cold face test in the assessment of trigeminal-brainstemvagal function in humans. Ann Neurol 1980; $7:$ 144-9.

20 Smeland EB, Owe JO, Andersen HT. Modification of the "diving bradycardia" by hypoxia or exercise. Respir Physiol 1984; 56: 245-51. 
21 Folgering $H$, Wijhheymer $P$, Geeraedts $L$. Diving bradycardia is not correlated to the oculocardiac reflex. Int $\mathbf{J}$ Sports Med 1983; 4: 166-9.

22 DeBurgh Daly $M$, Elsner R, Angell-James JE.

Cardiorespiratory control by carotid chemoreceptors during experimental dives in the seal. Am J Physiol 1977; 232: H508-16.

23 Elsner R, Angell-James JE, DeBurgh Daly M. Carotid body chemoreceptor reflexes and their interactions in the seal. Am J Physiol 1977; 232: H517-25.

24 Davidson NS, Goldner S, McCloskey DI. Respiratory modulation of baroreceptor and chemoreceptor reflexes affecting heart rate and cardiac vagal efferent nerve activity. $J$ Physiol 1976; 259: 523-30.

25 Gandevia SC, McCloskey DI, Potter EK. Reflex bradycardia occurring in response to diving, nasopharyngeal stimulation and ocular pressure, and its modification by respiration and swallowing. J Physiol 1978; 276: 383-94.

26 Blix AS, Folkow B. Cardiovascular adjustments to diving in mammals and birds. In: Shepherd JT, Abboud FM, Geiger SR (Eds.), The Cardiovascular System. Cambridge University Press, 1983: 917-45.

27 Kooyman GL, Castellini MA, Davis RW. Physiology of diving in marine mammals. Ann Rev Physiol 1981; 43: 343-56.

28 Miles TS. Features peculiar to the trigeminal innervation. Can J Neurol Sci 1979; 6: 95-103.

29 Hurwitz BE, Furedy $J J$. The human dive reflex: an experimental, topographical and physiological analysis. Physiol Behav 1986; 36: 287-94.

30 Scholander PF, Hammel HT, LeMessurier H, Hemmingsen $E$, Garey $W$. Circulatory adjustment in pearl divers. J Appl Physiol 1962; 17: 184-90.

31 Wolf $S$. The bradycardia of the dive reflex - a possible mechanism of sudden death. Trans Am Clin Assoc 1964; 76: 192-200.

32 Martin TG. Neardrowning and cold water immersion. Ann Emerg Med 1984; 13: 263-73.

33 Leivestad H, Andersen H, Scholander PF. Physiological response to air exposure in codfish. Nature 1957; 126: 505. 